\title{
Estimating the impact of climate change on the potential distribution of Indo-Pacific humpback dolphins with species distribution model
}

\author{
Jinbo Fu ${ }^{1}$, Linlin Zhao ${ }^{2}$, Changdong Liu ${ }^{\text {Corresp., } 1}{ }^{,}$Bin Sun ${ }^{1}$ \\ 1 Department of Fisheries, Ocean University of China, Qingdao, Shandong, China \\ 2 First Institute of Oceanography, Ministry of Natural Resources, Qingdao, Shandong, China \\ Corresponding Author: Changdong Liu \\ Email address: changdong@ouc.edu.cn
}

As IUCN critically vulnerable species, the Indo-Pacific humpback dolphins (Sousa chinensis) have attracted great public attention in recent years. The threats of human disturbance and environmental pollution to this population have been documented extensively. However, research on the sensitivity of this species to climate change is lacking. To understand the effect of climate change on the potential distribution of Sousa chinensis, we developed a weighted ensemble model based on 82 occurrence records and six predictor variables (e.g., ocean depth, distance to shore, mean temperature, salinity, ice thickness, and current velocity). According to the TSS and AUC values, our ensemble model presented higher prediction precision than most of the single-algorithm models. It also indicated that ocean depth and distance to shore were the most important predictors in shaping the distribution patterns. The projections for the 2050s and 2100 s from our ensemble model indicated a severe adverse impact of climate change on the Sousa chinensis habitat. Over $75 \%$ and $80 \%$ of the suitable habitat in the present day will be lost in all RCP scenarios in the 2050s and 2100s, respectively. With the increased numbers of records of stranding and deaths of Sousa chinensis in recent years, strict management regulations and conservation plans are urgent to safeguard the current suitable habitats. Due to habitat contraction and poleward shift in the future, adaptive management strategies, including designing new reserves and adjusting the location and range of reserves according to the geographical distribution of Sousa chinensis, should be formulated to minimize the impacts of climate change on this species. 
1 Estimating the impact of climate change on the potential distribution of

2 Indo-Pacific humpback dolphins with species distribution model

3

4 Jinbo $\mathrm{Fu}^{1}$, Linlin $\mathrm{Zhao}^{2}$, Changdong $\mathrm{Liu}^{1}$, Bin Sun ${ }^{1}$

51 Department of Fisheries, Ocean University of China, Qingdao, Shandong, China

62 First Institute of Oceanography, Ministry of Natural Resources, Qingdao, Shandong, China

7

8 Corresponding Author:

9 Changdong Liu ${ }^{1}$

10 Department of Fisheries, Ocean University of China, No.5, Yushan Road, Qingdao, Shandong,

11266003 , China

12 Email address: changdong@,ouc.edu.cn 
27 Abstract: As IUCN critically vulnerable species, the Indo-Pacific humpback dolphins (Sousa chinensis) have attracted great public attention in recent years. The threats of human disturbance and environmental pollution to this population have been documented extensively. However, research on the sensitivity of this species to climate change is lacking. To understand the effect

31 of climate change on the potential distribution of Sousa chinensis, we developed a weighted ensemble model based on 82 occurrence records and six predictor variables (e.g., ocean depth, distance to shore, mean temperature, salinity, ice thickness, and current velocity). According to the TSS and AUC values, our ensemble model presented higher prediction precision than most of the single-algorithm models. It also indicated that ocean depth and distance to shore were the most important predictors in shaping the distribution patterns. The projections for the 2050s and 2100s from our ensemble model indicated a severe adverse impact of climate change on the Sousa chinensis habitat. Over $75 \%$ and $80 \%$ of the suitable habitat in the present day will be lost in all RCP scenarios in the 2050s and 2100s, respectively. With the increased numbers of records of stranding and deaths of Sousa chinensis in recent years, strict management regulations and

41 conservation plans are urgent to safeguard the current suitable habitats. Due to habitat contraction and poleward shift in the future, adaptive management strategies, including designing new reserves and adjusting the location and range of reserves according to the geographical distribution of Sousa chinensis, should be formulated to minimize the impacts of climate change on this species.

Keywords: Sousa chinensis, Marine fauna, Greenhouse gas emissions, Climate impact, Future 


\section{Introduction}

As the most concerning environmental issue, global climate change has caused significant changes in marine environmental conditions over the past decades (Belkin, 2009; Cheung et al., 2013; Wu, 2020). For instance, the assessment that was made for the coastal China seas over the 21st century shows that the East China Sea (ECS) will be simultaneously exposed to enhanced warming, deoxygenation, acidification, and decreasing net primary productivity (NPP) as a consequence of increasing greenhouse gas emissions (Tan et al., 2020). A species lives on a certain environmental niche space, so the change of the dependent environment conditions may change the distribution of this species (Bellard et al., 2012; Faleiro et al., 2018). The distributions of marine mammals have been impacted significantly by the environmental change over the past decades (Nøttestad et al., 2015; Chen et al., 2020). According to these facts, understanding how future climate change will influence species distributions is vital for the better protection of species.

Species distribution models (SDMs) build species-environment relationships that are typically based on species location data (e.g., abundance and occurrence) and environmental variables that are thought to influence species distributions and can provide a useful framework for identifying and evaluating the habitat suitability for a given species (Guisan \& Thuiller, 2005). Currently, SDMs are applied broadly in the life and environmental science fields (Cheung et al., 2009; Robinson et al., 2011). For example, multiple types of SDM are available to predict the impacts of climate change on species distributions (Zhang et al., 2019), to assess how habitat loss restricts large-scale species distribution (Vasconcelos \& Doro, 2016), to understand 
69 biological invasions (Zhang et al., 2020) and to site aquaculture farms (Dong et al., 2020).

70 Accordingly, the use of SDMs in conservation biology and biodiversity assessments is ever-

71 increasing (Pereira et al., 2018; Araújo et al., 2019; Zhang et al., 2020b).

72 Indo-Pacific humpback dolphins (Sousa chinensis), also known as "mermaids" and "water

73 pandas", belong to the porpoise family of cetaceans (Jefferson \& Karczmarski, 2001). Due to

74 their preferred inshore and estuarine habitats, Sousa chinensis are typically found in the shallow,

75 coastal waters of the Indian and western Pacific oceans (Jefferson \& Rosenbaum, 2014; Jefferson

76 \& Smith, 2016; Parra \& Jefferson, 2018). These areas, which have intensive commercial

77 fisheries, are usually rapidly developing and are easily polluted by industrial production and

78 daily activities of residents (Karczmarski, 2000; Chen et al., 2008; Wu \& Chen, 2014;

79 Karczmarski et al., 2016; Guo et al., 2020; Li, 2020); the corresponding consequences of habitat

80 degradation may lead to population declines of Sousa chinensis or even put this species at risk of

81 extinction. In recent years, the numbers of records on strandings or deaths of Sousa chinensis

82 have increased in China (Chen et al., 2008; Guo et al., 2020). This species has already been

83 classified as "vulnerable" by the International Union for Conservation of Nature (Jefferson et al.,

84 2017). Consequently, formulating a conservation plan for Sousa chinensis is urgent under current

85 and future environmental scenarios. Predicting the geographical distribution for the present and

86 future is a prerequisite for plan formulation (Schickele et al., 2020).

87 In this study, we developed ten individual SDMs. We then built a weighted average

88 ensemble model, which has not been used to identify the potential distributions of Sousa

89 chinensis under present-day and future climate scenarios. Our ensemble model was expected to 
present a better performance in predictive accuracy and uncertainty reduction than each individual model. We hypothesize the suitable habitats of Sousa chinensis will contract and shift poleward because of climate change in the future. Our ensemble model can help us to 1) determine the important environmental variables that affect Sousa chinensis distributions, 2) map the environmental suitability for Sousa chinensis under present-day and future climate scenarios, and 3) assess the impacts of climate change on Sousa chinensis habitat distributions. Our study can provide important implications for formulating adaptive management strategies, including designing new reserves and adjusting the location and range of reserves according to the geographical distribution of Sousa chinensis under current and future scenarios and an important reference to solve marine conservation planning problems. It also provides guidance for research on the potential distributions of other protected species under future climate change scenarios.

\section{Materials and methods}

2.1 Study area and Sousa chinensis data collection

Indo-Pacific humpback dolphins (Sousa chinensis) are mainly distributed in the Western Pacific and the Indian Ocean, so our research is located in these areas (i.e., $50^{\circ} \mathrm{E}$ to $180^{\circ} \mathrm{E}, 50^{\circ} \mathrm{S}$ to $50^{\circ} \mathrm{N}$; Fig. 1). Georeferenced species data (presence) were obtained from the online database: Global Biodiversity Information Facility (GBIF, https://www.gbif.org) and Ocean Biogeographic Information System (OBIS, https://obis.org). The cluster samples in a $5 \times 5$ arc-minute grid consistent with the spatial resolution of environmental data are removed; only one record per grid unit is used to avoid over-representation of environmental conditions (sampling bias) in densely sampled areas. A total of 124 incidents were retrieved, 82 of which were within our 
111 study area.

$112 \quad 2.2$ Environmental variables and future projections

113 The raster data of environmental variable projections in this study were retrieved from the

114 Bio-ORACLE v2.1 dataset (http://www.bio-oracle.org) (Assis et al., 2018) and Global Marine

115 Environment Datasets (http://gmed.auckland.ac.nz) (Basher et al., 2014). The mean chlorophyll,

116 velocity, salinity, temperature, dissolved oxygen content, ice thickness, and $\mathrm{pH}$ data were

117 obtained from Bio-ORACLE. The distance to shore and mean ocean depth data were obtained

118 from GMED. In addition, the annual ranges of chlorophyll, flow rate, salinity, temperature,

119 dissolved oxygen, and ice thickness were also obtained from Bio-ORACLE. There were a total

120 of 15 environmental variables with a spatial resolution of $5 \times 5$ arc-minutes (i.e., $9.2 * 9.2 \mathrm{~km}$ at

121 the equator). Pearson correlation analysis was conducted for these 15 environmental variables to

122 reduce the influence of collinearity on the precision of model predictions. By comprehensive

123 consideration of the availability of current and future environmental data, six low-correlation

124 (pairwise Pearson's correlation coefficients were less than |0.7|) (Dormann et al., 2013)

environmental variables, including mean current velocity, mean salinity, mean temperature,

mean ice thickness, mean ocean depth and distance to shore, were finally selected for the

modeling analysis (Fig. S1).

Meanwhile, the projections of the first four environmental variables for the future (i.e.,

2040-2050 (the 2050s) and 2090-2100 (the 2100s)) under four representative concentration

pathway emission scenarios (RCPS) were also retrieved from the Bio ORACLE v2.1 dataset.

RCPs (i.e., RCP26, RCP45, RCP65, and RCP85) are new climate change scenarios on radiation 
132 forcing at the end of the 20th century that were published in the fifth assessment report of the

133 Intergovernmental Panel on Climate Change (IPCC). RCP26 indicates an optimistic emission

134 level resulting in low greenhouse gas concentration; RCP45 and RCP60 represent the moderate

135 emission level; and RCP85 indicates an pessimistic emission level leading to the highest

greenhouse gas concentration (Moss et al., 2010). We assumed that distance to shore and ocean depth remain constant in the future. Future temperature, salinity, ice thickness, and current velocity) in Bio-ORACLE were predicted based on the mean simulation results of three Atmosphere-Ocean General Circulation Models (AOGCMs), i.e., Community Climate System

Model (CCSM4, National Center for Atmospheric Research), Hadley Center Global

Environment Model, version 2 (HadGEM2-ES, Met Office Hadley Centre) and Model for

Interdisciplinary Research on Climate, version 5 (MIROC5, Atmosphere and Ocean Research

Institute, National Institute for Environmental Studies, and Japan Agency for Marine-Earth

Science and Technology) from the Coupled Model Intercomparison Project 5 (CMIP 5) (Assis et

al., 2018; Sharma et al., 2021). We believed the mean results of three different AOGCMs can

reduce the uncertainties effectively. The changes in the four predictor variables in the future (i.e.,

the 2050s and the 2100s) under different scenarios are shown in Table 1.

2.3 Modeling procedures

We conducted the model analysis on the R platform based on the "biomod2" package, and ten SDMs were available in this package (Thuiller et al., 2020). The ten models include the generalized linear model (GLM) (McCullagh \& Nelder, 1989), generalized additive model

152 (GAM) (Hastie \& Tibshirani, 1990), classification tree analysis (CTA) (Breiman et al., 1984), 
153 generalized enhanced regression model (GBM) (Ridgeway, 1999), artificial neural network

154 (ANN) (Lek \& Guégan, 1999), surface range envelope (SRE) (Breiman, 2001a), flexible

155 discriminant analysis (FDA) (Hastie et al.,1994), multiple adaptive regression splines (MARS)

156 (Friedman, 1991), random forest (RF) (Breiman, 2001b), and maximum entropy model (Maxent)

157 (Phillips et al., 2006).

Due to the lack of true absence records, we simulated 5000 pseudo-absence points randomly in contrasting environmental conditions with the true presence points (Guisan et al., 2017; Thuiller et al., 2020). A fivefold cross-validation technique with 10 repetitions was used to assess the model prediction accuracy (Guisan et al., 2017; Thuiller et al., 2020). Based on this approach, $80 \%$ of the dataset was randomly selected for calibration and testing of the models, and $20 \%$ was withheld for evaluation of the model predictions. Two indicators were used to evaluate the predictive capability of each model: the true skill statistic (TSS) (Allouche et al., 2006) and the area under the receiver operating characteristic curve (AUC) (Swets, 1988). To ensure sufficient prediction accuracy, the models with mean TSS value above 0.80 and mean

AUC value above 0.85 were reserved for further analyses (Zhang et al., 2019). build a weighted average ensemble model predicting the Sousa chinensis distributions under present and future climate conditions based on the "biomod2" package (Zurell et al., 2020). For a better interpretation of model outcomes, continuous habitat suitability projections were converted into binary maps (e.g., suitable/unsuitable) by using an automatically generated 
174

175

176

177

178

179

180

181

182

183

184

185

186

187

2017; Zhang et al., 2020b).

The relative importance of each environmental variable in predicting the Sousa chinensis distributions was determined by a randomized approach. This approach computes the Pearson correlations among predictions using all predictor variables and predictions in which the predictor variable being evaluated was randomly permutated (Guisan et al., 2017; Thuiller et al., 2020). Low correlations between the standard predictions and those using the permuted variable indicate the high importance of a predictor variable (Zhang et al., 2019). A response curve, which describes the variations in species occurrence probability along the gradient of each important predictor variable, was plotted.

\section{Result}

3.1 Model performances and predictive accuracy of SDMs

The different AUC and TSS values indicated the different predictive performances among all 10 modeling algorithms. All the models except SRE, MAXENT and FDA exhibited good predictive capacity and were selected to construct the ensemble model (Figs. S2 and S3). The AUC and TSS values of all the individual models except GBM and RF were lower than those of the ensemble model (AUC: 0.993, TSS: 0.963), which demonstrated the superior predictive performance of the ensemble model.

\subsection{Response curve and variable importance}

The six predictor variables made different contributions to the Sousa chinensis distributions. Among the six predictor variables, depth $(0.435 \pm 0.029)$ and distance to shore $(0.473 \pm 0.031)$ were the two most important variables for the model predictions. The contributions of 
195

196

\section{Discussion}

temperature $(0.234 \pm 0.018)$, salinity $(0.135 \pm 0.013)$, and current velocity $(0.080 \pm 0.011)$ were moderate, while ice thickness $(0.003 \pm 0.0007)$ was considered to be nearly irrelevant (Fig. S4).

The response curves of Sousa chinensis to the three most important variables from the ten models (except SRE) are shown in Fig. S5. The response curves indicated that the environmental requirements of Sousa chinensis in the different models were generally similar.

3.3 Potential distributions under present and future climate scenarios

Our prediction of suitable habitat for Sousa chinensis under present climate conditions is shown in Fig. 1. All of the occurrence records were within the predicted suitable range. The predictions show that a large part of the coastal areas of the Southeast Asian countries and northern Australia are suitable habitats for Sousa chinensis. Some of the occurrence records were located in the coastal areas of the Indian Peninsula.

As the model results show, the suitable area for Sousa chinensis will decrease under all four assumed future climate change scenarios. Future habitat projections under different RCP scenarios show different distribution patterns and consistently suitable range contraction for Sousa chinensis (Table 2). The model projections indicate that the contraction of the suitable range of this species could be from $75.626 \%$ (under the RCP2.6 scenario in the 2050s) to 95.815\% (under the RCP8.5 scenario in the 2100s). Future predictions for the 2100s show that environmental conditions suitable for Sousa chinensis will shift northward to the East China Sea and south coast of Japan. The equatorial sea area and coastal area of northern Australia are predicted to be less suitable for this species (Fig. 2). 
216

217

218

219

220

221

222

223

224

225

226

227

228

229

230

231

232

233

234

235

4.1 Model performance

Utilizing georeferenced presence/pseudo-absence data and the corresponding environmental data, we developed an ensemble model for Sousa chinensis to predict the present and future potential distributions of this rare species. The results demonstrate that our ensemble model performed well in predicting the habitat suitability for Sousa chinensis under the present environmental conditions. The model predictions indicated that the potential distribution of Sousa chinensis will contract in the future under all the RCP scenarios and that the suitable habitat in the Indo-Pacific Mid-Seas will shift to higher latitudes.

Many mature models can be used to predict species distributions. The most commonly used method is to select the best model based on performance indicators such as TSS and AUC and then use the single best model to predict species distributions. Due to the higher accuracy and reliability compared to individual models, several published studies recommended using ensemble model to predict potential species distribution and habitat suitability (Araújo \& New, 2007; Thuiller et al., 2009; César \& Pedro, 2011; Shabani et al., 2016). In this study, the weighted ensemble model performed better than most of the individual models but was not the best in predictive performance, and this finding was consistent with the previous study (Hao et al., 2020). The ensemble model is built based on the weighted average of individual models, so this model will present an advantage over individual models in reducing the uncertainties of model results.

4.2 Climate change and associated distribution shift

Peer) reviewing PDF | (2021:05:60878:1:1:NEW 18 Jul 2021) 

expected (e.g., the coast of Malaysia). Suitable habitats were also found beyond where the species have been recorded, and this phenomenon can be caused by many factors, such as biotic interactions, dispersal limitation of species, niche size, and sampling bias ( Pulliam, 2000;

Goldsmit et al., 2018). Published studies have reached similar conclusions in predicting species distributions using SDM (Goldsmit et al., 2018; Zhang et al., 2020a). As shown in the binary output of habitat prediction, the main Sousa chinensis habitat in China is located in the Pearl River Estuary in Guangdong Province. The Pearl River Estuary is an intersection area of brackish and freshwater that results in fertile water quality and high primary productivity. The suitable temperatures and salinities, as well as the low pollution, high biodiversity, and unexploited natural shorelines, all make this area a favorite for Sousa chinensis.

AOGCMs provided by CMIP 5, we determined the changes in four available environmental variables. As shown in Table 1, temperatures will increase with different amplitudes under different RCPs. This tendency of global warming will severely affect Sousa chinensis distributions in terms of range size, e.g., it will probably lead to a reduction of more than fourfifths of its range in the 2100s. Meanwhile, the suitable Sousa chinensis habitat in the future will shift northward. In China, the suitable habitat on the southern coast will shift to the east Yellow

Sea and even to the coastal areas of Bohai Bay. Tan et al. (2020) assessed the East China Sea

255 (ECS). They found that climate change caused by increasing greenhouse gas emissions will 
257

258

259

260

261

262

263

264

265

266

267

268

269

270

271

272

273

274

275

276

277

ocean areas that are most vulnerable to future climate change. For example, the rising sea

temperature and the change of dissolved oxygen content in the ECS affected the metabolic

process of marine organisms and brought significant changes in the abundance and geographical distribution of marine life (Stenseth et al., 2002; Walther et al., 2002). On the other hand, the habitat in areas around Australia will shift southward in the future. The areas off the coast of

Malaysia will no longer be suitable for Sousa chinensis. This trend toward higher latitudes is similar to that described in the formal research (e.g., Ruiz-Navarro et al., 2016; Zhang et al., 2019, 2020c). Regardless of the dispersal scenario, our results highlight the high vulnerability of this critically vulnerable species to climate change.

4.3 Impact factors of Sousa chinensis distribution

Due to the intricate relationships among survival, growth and environmental conditions, many factors may affect the habitat distributions of Sousa chinensis. The basic niche that is suitable for the growth of Sousa chinensis, such as water temperature, water depth, and distance from shore, was considered in this study. The distribution of Sousa chinensis is negatively correlated with distance from shore and distance from the main estuary (Chen et al., 2020); hence, estuaries have been identified as their preferred habitat (Jefferson \& Karczmarski, 2001; Wang et al., 2007; Chen et al., 2008; Jefferson \& Smith, 2016). Environmental change induced by climate change may also affect the distributions of bait fishes and will indirectly affect Sousa chinensis distributions (Schickele et al., 2020).

Human activities have great impacts on Sousa chinensis habitats. The coastal areas of the China Sea, with many estuaries, bays, coral reefs and fisheries, are not only suitable habitats for 
278 Sousa chinensis but are also the most active areas for developing the maritime economy. Fishing

279 behavior and boat travel have been determined to cause stranding deaths of Sousa chinensis (Guo

280 et al. 2020). Sousa chinensis proved to be more acoustically active and prefer locations with

281 lower noise levels (Caruso et al., 2020a; Caruso et al., 2020b). However, human activities often

282 generate underwater noise, which interferes with information exchange with conspecifics and

283 interaction with the surrounding environment and can even lead to behavioral disorders (Xu et

284 al., 2020). Meanwhile, Sousa chinensis prefer waters near the natural coastline, while human

285 activities such as sea reclamation would change the type of coastline and reduce the length of the

286 natural coastline. Since the middle of the last century, the proportion of natural coastlines in

287 China has continued to decline (Hou et al., 2016), which makes it more difficult for Sousa

288 chinensis to find their preferred habitats and makes this sensitive species more vulnerable to

289 extinction.

290 4.4 Conservation suggestions

291 Our results indicated that over $75 \%$ and $80 \%$ of the suitable habitat for Sousa chinensis in

292 the present-day would be lost in all RCP scenarios in the 2050s and 2100s, respectively. The

293 results may be inflated by the high over prediction of the models due to the few environmental

294 variables used and not accounting for the biotic variables influencing Sousa chinensis

295 distribution. Meanwhile, areas, where the species have never been observed in the current

296 climate conditions and were lost in the future climate scenarios may also inflate the results.

297 However, the change of marine environment induced by climate change will undoubtedly cause 
298

299

300

301

302

303

304

305

306

307

308

309

310

311

312

313

314

315

316

317

habitat reduction and poleward in the future. Therefore, adaptive management strategies are important for minimizing the impact of climate change on this vulnerable species.

Protected areas have been considered to be effective in situ strategy for conserving biodiversity and ecosystem services (Wang \& Li, 2021). As a vulnerable species with great public concern, conservation attention has been given to Sousa chinensis. Seven natural reserves have been set up for this species (Indo-Pacific Humpback Dolphins Conservation Program (2017-2026)) in China. The adverse effects of climate change on the protected areas of many amphibian species and Chinese giant salamander (Andrias davidianus) have been elucidated (e.g., D'Amen et al., 2011; Zhang et al., 2020b). The same situation will possibly occur in the protected areas for marine mammals such as Sousa chinensis. For instance, Hunt et al. (2020) used SDMs to predict the Sousa chinensis distribution in the marine reserve in Australia and evaluated that the effect in the established reserve will be reduced. Based on the present prediction of Sousa chinensis distribution in this study, we suggest establishing new reserves and limiting human and industrial activities in the important habitats in the short term. Based on the predicted distribution for future, we suggest formulating adaptive management strategies, including restoring the damaged habitats, adjusting the reserve range and location according to the change of distribution, and pre-establishing conservation areas in the long term. For example, the coastal areas of the East Yellow Sea in China should be protected to prepare for the possible poleward shift of Sousa chinensis distribution.

\section{Conclusion}


318 In this study, we developed a weighted average ensemble model based on 82 occurrence

319 records and six predictor variables to predicted the potential distribution of Sousa chinensis

under current and future climate scenarios. Our results indicated that over $75 \%$ and $80 \%$ of the

suitable habitats in the present-day would be lost in all RCP scenarios in the 2050s and 2100s,

respectively. The contraction and shift poleward of suitable habitats in the future imply that

adaptive management strategies are important for minimizing the impact of climate change on

Sousa chinensis. The results from our study can be used as references to formulate specific

protection plans, such as designing new reserves and adjusting the current reserves.

326

327

328

329

330

331

332

333

334

335

336

337

338

\section{Acknowledgments}

We thank Global Biodiversity Information Facility (GBIF, https://www.gbif.org), Ocean

Biogeographic Information System (OBIS, https://obis.org), Bio-ORACLE v2.1 dataset

(http://www.bio-oracle.org) and Global Marine Environment Datasets

(http://gmed.auckland.ac.nz) for providing the data to us.

\section{References}

Allouche O, Tsoar A, Kadmon R. 2006. Assessing the accuracy of species distribution models: prevalence, kappa and the true skill statistic (TSS). Journal of Applied Ecology 43:12231232. DOI: $10.1111 / \mathrm{j} .1365-2664.2006 .01214 . \mathrm{x}$

Araujo MB, New M. 2007. Ensemble forecasting of species distributions. Trends in Ecology \& Evolution 22:42-47. DOI: 10.1016/j.tree.2006.09.010

Araujo MB, Anderson RP, Barbosa AM, Beale CM, Dormann CF, Early R, Garcia RA, Guisan A, Maiorano L, Naimi B, O'Hara RB, Zimmermann NE, Rahbek C. 2019. Standards for 
distribution models in biodiversity assessments. Science Advances 5. DOI: 10.1126/sciadv.aat4858

341

342

343

344

345

346

347

348

349

350

351

352

353

354

355

356

357

358

359

Assis J, Tyberghein L, Bosch S, Verbruggen H, Serrao EA, De Clerck O. 2018. Bio-ORACLE v2.0: Extending marine data layers for bioclimatic modelling. Global Ecology and Biogeography 27:277-284. DOI: 10.1111/geb.12693

Basher, Z., Bowden, D.A., Costello, M.J., 2014. Global marine environment dataset (GMED). Version 1.0 (Rev.01.2014). Available from http://gmed.auckland.ac.nz (accessed 30 October 2018).

Belkin IM. 2009. Rapid warming of Large Marine Ecosystems. Progress in Oceanography 81:207-213. DOI: 10.1016/j.pocean.2009.04.011

Bellard C, Bertelsmeier C, Leadley P, Thuiller W, Courchamp F. 2012. Impacts of climate change on the future of biodiversity. Ecology Letters 15:365-377. DOI: 10.1111/j.14610248.2011.01736.x

Breiman L, Friedman JH, Olshean RA, Stone CJ, 1984. Classification and Regression Trees. Chapman and Hall, London. DOI: 10.1002/widm.8

Breiman L. 2001a. Random forests. Machine Learning 45:5-32. DOI:

$$
\text { 10.1023/A:1010933404324 }
$$

Breiman L. 2001b. Statistical modeling: The two cultures. Statistical Science 16:199-215. DOI:

$$
10.1214 / \mathrm{ss} / 1009213726
$$

Cai RS, Chen JL, Huang RH. 2006. The response of marine environment in the offshore area of China and its adjacent ocean to recent global climate change. CHINESE JOURNAL OF 
ATMOSPHERIC SCIENCES-CHINESE EDITION-, 30(5), 1019.

361 Capinha C, Anastacio P. 2011. Assessing the environmental requirements of invaders using ensembles of distribution models. Diversity and Distributions 17:13-24. DOI: 10.1111/j.1472-4642.2010.00727.x

Caruso F, Dong LJ, Lin ML, Liu MM, Gong ZN, Xu WX, Aionge G, Li SH. 2020a. Monitoring of a Nearshore Small Dolphin Species Using Passive Acoustic Platforms and Supervised Machine Learning Techniques. Frontiers in Marine Science 7. DOI: 10.3389/fmars.2020.00267

Caruso F, Dong LJ, Lin ML, Li MM, Xu WX, Li SH. 2020b. Influence of acoustic habitat variation on Indo-Pacific humpback dolphin ( Sousa chinensis ) in shallow waters of Hainan Island, China . The Journal of the Acoustical Society of America, 147(6), 3871-3882. DOI:

Chen BY, Hong Z, Hao XQ, Gao HL. 2020. Environmental models for predicting habitat of the Indo-Pacific humpback dolphins in Fujian, China. Aquatic Conservation-Marine and Freshwater Ecosystems 30:787-793. DOI: 10.1002/aqc.3279

Chen BY, Zheng DM, Zhai FF, Xu X, Sun P, Wang Q, Yang G. 2008. Abundance, distribution and conservation of Chinese White Dolphins (Sousa chinensis) in Xiamen, China. Mammalian Biology 73:156-164. DOI: 10.1016/j.mambio.2006.12.002

Cheung WWL, Lam VWY, Sarmiento JL, Kearney K, Watson R, Pauly D. 2009. Projecting global marine biodiversity impacts under climate change scenarios. Fish and Fisheries 10:235-251. DOI: 10.1111/j.1467-2979.2008.00315.x 
381 Cheung WWL, Watson R, Pauly D. 2013. Signature of ocean warming in global fisheries catch.

382

383

384

385

386

387

388

389

390

391

392

393

394

395

396

397

398

399

400

401
Nature 497:365-+. DOI: 10.1038/nature12156

D'Amen M, Bombi P, Pearman PB, Schmatz DR, Zimmermann NE, Bologna MA. 2011. Will climate change reduce the efficacy of protected areas for amphibian conservation in Italy? Biological Conservation 144:989-997. DOI: 10.1016/j.biocon.2010.11.004

Dong JY, Hu CY, Zhang XM, Sun X, Zhang PD, Li WT. 2020. Selection of aquaculture sites by using an ensemble model method: a case study of Ruditapes philippinarums in Moon Lake. Aquaculture 519. DOI: 10.1016/j.aquaculture.2019.734897

Dormann CF, Elith J, Bacher S, Buchmann C, Carl G, Carre G, Marquez JRG, Gruber B, Lafourcade B, Leitao PJ, Munkemuller T, McClean C, Osborne PE, Reineking B, Schroder B, Skidmore AK, Zurell D, Lautenbach S. 2013. Collinearity: a review of methods to deal with it and a simulation study evaluating their performance. Ecography 36:27-46. DOI: 10.1111/j.1600-0587.2012.07348.x

Faleiro FV, Nemesio A, Loyola R. 2018. Climate change likely to reduce orchid bee abundance even in climatic suitable sites. Global Change Biology 24:2272-2283. DOI:

$10.1111 / \mathrm{gcb} .14112$

Friedman JH. 1991. Multivariate Adaptive Regression Splines - Rejoinder. Annals of Statistics 19:123-141. DOI: $10.1214 / \operatorname{aos} / 1176347973$

Goldsmit J, Archambault P, Chust G, Villarino E, Liu G, Lukovich JV, Barber DG, Howland KL. 2018. Projecting present and future habitat suitability of ship-mediated aquatic invasive species in the Canadian Arctic. Biological Invasions 20:501-517. DOI: 10.1007/s10530-

Peer) reviewing PDF | (2021:05:60878:1:1:NEW 18 Jul 2021) 
Guisan A, Thuiller W. 2005. Predicting species distribution: offering more than simple habitat models. Ecology Letters 8:993-1009. DOI: 10.1111/j.1461-0248.2005.00792.x

Guisan A, Thuiller W, Zimmermann NE. 2017. Habitat Suitability and Distribution Models (With Applications in R) || Environmental Predictors: Issues of Processing and Selection. DOI:10.1017/9781139028271.011

Guo L, YU Q, LI Z, Sun L, Wang Y, Zheng Y, Zhang T, 2020. Study on the Survival Status of Chinese White Dolphins in the Pearl River Estuary. Popular Science (10), 18-20+57.

Hastie TJ, Tibshirani RJ. 1990. Generalized additive models (Vol. 43). CRC press.

Hastie T, Tibshirani R, Buja A. 1994. Flexible Discriminant-Analysis by Optimal Scoring. Reports 10. DOI: 10.1038/s41598-020-69863-6

Jefferson TA, Karczmarski L. 2001. Sousa chinensis. Mammalian Species, 655(655), 1-9. DOI: 
424

425

426

427

428

429

430

431

432

433

434

435

436

437

438

439

440

441

442

443

Jefferson TA, Rosenbaum HC. 2014. Taxonomic revision of the humpback dolphins (Sousa spp.), and description of a new species from Australia. Marine Mammal Science 30:14941541. DOI: $10.1111 / \mathrm{mms} .12152$

Jefferson TA, Smith BD. 2016. Re-assessment of the Conservation Status of the Indo-Pacific Humpback Dolphin (Sousa chinensis) Using the IUCN Red List Criteria. Humpback Dolphins (Sousa Spp): Current Status and Conservation, Pt 2 73:1-26. DOI: 10.1016/bs.amb.2015.04.002

Jefferson TA, Smith BD, Braulik GT, Perrin W. 2017. Sousa chinensis (errata version published in 2018). The IUCN Red List of Threatened Species 2017: e.T82031425A123794774. DOI: 10.2305/IUCN.UK.2017-3.RLTS.T82031425A50372332.en

Karczmarski L, Huang SL, Or CKM, Gui D, Chan SCY, Lin WZ, Porter L, Wong WH, Zheng RQ, Ho YW, Chui SYS, Tiongson AJC, Mo YQ, Chang WL, Kwok JHW, Tang RWK, Lee ATL, Yiu SW, Keith M, Gailey G, Wu YP. 2016. Humpback Dolphins in Hong Kong and the Pearl River Delta: Status, Threats and Conservation Challenges. Humpback Dolphins (Sousa Spp): Current Status and Conservation, Pt 2 73:27-64. DOI:

10.1016/bs.amb.2015.09.003

Lek S, and Guegan JF. 1999. Artificial neural networks as a tool in ecological modelling, an introduction. Ecological Modelling 120:65-73. DOI: 10.1016/S0304-3800(99)00092-7 
444 Liu CR, White M, Newell G. 2013. Selecting thresholds for the prediction of species occurrence with presence-only data. Journal of Biogeography 40:778-789. DOI: 10.1111/jbi.12058

446

447

448

449

450

451

452

453

454

455

456

457

458

459

460

461

462

463

464

McCullagh P, Nelder J, 1989. Generalized linear models, 2nd edition. Chapman and Hall, London.

Moss RH, Edmonds JA, Hibbard KA, Manning MR, Rose SK, van Vuuren DP, Carter TR, Emori S, Kainuma M, Kram T, Meehl GA, Mitchell JFB, Nakicenovic N, Riahi K, Smith SJ, Stouffer RJ, Thomson AM, Weyant JP, Wilbanks TJ. 2010. The next generation of scenarios for climate change research and assessment. Nature 463:747-756. DOI: 10.1038 /nature08823

Nottestad L, Krafft BA, Anthonypillai V, Bernasconi M, Langard L, Mork HL, Ferno A. 2015. Recent changes in distribution and relative abundance of cetaceans in the Norwegian Sea and their relationship with potential prey. Frontiers in Ecology and Evolution 2. DOI:10.3389/fevo.2014.00083

Parra, Guido J. (2018). Encyclopedia of Marine Mammals || Humpback Dolphins. , (), 483489. DOI:10.1016/B978-0-12-804327-1.00153-9

Phillips SJ, Anderson RP, Schapire RE. 2006. Maximum entropy modeling of species geographic distributions. Ecological Modelling 190:231-259. DOI: 10.1016/j.ecolmodel.2005.03.026

Pulliam HR. 2000. On the relationship between niche and distribution. Ecology Letters 3:349361. DOI: 10.1046/j.1461-0248.2000.00143.x

R Development Core Team, 2020. R: A Language and Environment for Statistical Computing. R 
Foundation for Statistical Computing, Vienna, Austria Version 4.0.1.

466

467

468

469

470

471

472

473

474

475

476

477

478

479

480

481

482

483

484

485

Ridgeway G. 1999. The state of boosting. Computing science and statistics, 172-181.

Robinson LM, Elith J, Hobday AJ, Pearson RG, Kendall BE, Possingham HP, Richardson AJ.

2011. Pushing the limits in marine species distribution modelling: lessons from the land present challenges and opportunities. Global Ecology and Biogeography 20:789-802. DOI:

$10.1111 /$ j. $1466-8238.2010 .00636 . x$

Ruiz-Navarro A, Gillingham PK, Britton JR. 2016. Predicting shifts in the climate space of freshwater fishes in Great Britain due to climate change. Biological Conservation 203:33-

42. DOI: $10.1016 /$ j.biocon.2016.08.021

Schickele A, Leroy B, Beaugrand G, Goberville E, Hattab T, Francour P, Raybaud V. 2020. Modelling European small pelagic fish distribution: Methodological insights. Ecological Modelling 416. DOI: 10.1016/j.ecolmodel.2019.108902

Shabani F, Kumar L, Ahmadi M. 2016. A comparison of absolute performance of different correlative and mechanistic species distribution models in an independent area. Ecology and Evolution 6:5973-5986. DOI: 10.1002/ece3.2332

Sharma A, Dubey VK, Johnson JA, Rawal YK, Sivakumar K. 2021. Is there always space at the top? Ensemble modeling reveals climate-driven high-altitude squeeze for the vulnerable snow trout Schizothorax richardsonii in Himalaya. Ecological Indicators, 120, 106900. DOI: $10.1016 /$ j.ecolind.2020.106900

Stenseth NC, Mysterud A, Ottersen G, Hurrell JW, Chan KS, Lima M. 2002. Ecological effects of climate fluctuations. Science 297:1292-1296. DOI: 10.1126/science.1071281 
486 Swets JA. 1988. Measuring the accuracy of diagnostic systems. Science, 240(4857), 1285-1293.

487

488

489

490

491

492

493

494

495

496

497

498

499

500

501

502

503

504

505

506

DOI: $10.1126 /$ science. 3287615

Tan HJ, Cai RS, Huo YL, Guo HX. 2020. Projections of changes in marine environment in coastal China seas over the 21(st) century based on CMIP5 models. Journal of Oceanology and Limnology 38:1676-1691. DOI: 10.1007/s00343-019-9134-5

Thuiller W, Lafourcade B, Engler R, Araujo MB. 2009. BIOMOD - a platform for ensemble forecasting of species distributions. Ecography 32:369-373. DOI: 10.1111/j.16000587.2008.05742.x

Thuiller W, Georges D, Engler R, 2020. biomod2: ensemble platform for species distribution modeling. R package version 3.4.6.

Vasconcelos TS, Doro JLP. 2016. Assessing how habitat loss restricts the geographic range of Neotropical anurans. Ecological Research 31:913-921. DOI: 10.1007/s11284-016-1401-8

Walther GR, Post E, Convey P, Menzel A, Parmesan C, Beebee TJC, Fromentin JM, HoeghGuldberg O, Bairlein F. 2002. Ecological responses to recent climate change. Nature 416:389-395. DOI: 10.1038/416389a

Wang W, Li JS. 2021. In-situ conservation of biodiversity in China: Advances and prospects. Biodiversity Science, 29(2), 133-149. DOI: 10.17520/BIODS.2020070

Wu J, Chen Y, 2014. Preliminary discussion of medical care of stranded Chinese humpback dolphin. Chinese Journal of Wildlife, 35(2), 172-174

Wu LX. 2020. Acceleration of global mean ocean circulation under the climate warming. Science China-Earth Sciences 63:1039-1040. DOI: 10.1007/s11430-020-9610-9 
507

508

509

510

511

512

513

514

515

516

Xiao Y, 2020. Existing population and current status of Chinese white dolphins. Ocean and Fisheries (02), 20-21.

Xu WX, Dong LJ, Caruso F, Gong ZN, Li SH. 2020. Long-term and large-scale spatiotemporal patterns of soundscape in a tropical habitat of the Indo-Pacific humpback dolphin (Sousa chinensis). Plos One 15. DOI: 10.1371/journal.pone.0236938

Zhang ZX, Capinha C, Karger DN, Turon X, MacIsaac HJ, Zhan AB. 2020a. Impacts of climate change on geographical distributions of invasive ascidians. Marine Environmental Research 159. DOI: $10.1016 /$ j.marenvres.2020.104993

Zhang ZX, Mammola S, Liang ZQ, Capinha C, Wei QW, Wu YN, Zhou J, Wang CR. 2020b. Future climate change will severely reduce habitat suitability of the Critically Endangered Chinese giant salamander. Freshwater Biology 65:971-980. DOI: 10.1111/fwb.13483

Zhang ZX, Mammola S, Xian WW, Zhang H. 2020c. Modelling the potential impacts of climate change on the distribution of ichthyoplankton in the Yangtze Estuary, China. Diversity and Distributions 26:126-137. DOI: 10.1111/ddi.13002

Zhang ZX, Xu SY, Capinha C, Weterings R, Gao TX. 2019. Using species distribution model to predict the impact of climate change on the potential distribution of Japanese whiting Sillago japonica. Ecological Indicators 104:333-340. DOI: 10.1016/j.ecolind.2019.05.023

Zurell D, Franklin J, König C, Bouchet PJ, Serra-Diaz JM, Dormann CF, Elith J, Fandos Guzman G, Feng X, Guillera-Arroita G, Guisan A, Leitão PJ, Lahoz-Monfort JJ, Park DS, Peterson AT, Rapacciuolo G, Schmatz DR, Schröder B, Thuiller W, Yates KL, Zimmermann NE, Merow C. 2020. A standard protocol for describing species distribution 
models. Ecography. DOI: 10.1111/ecog.04960 


\section{Figure 1}

Binary output of habitat suitability and predicted potential distribution under current climate conditions of Sousa chinensis.

(A) Binary output of habitat suitability under current climate conditions. (B) Predicted current potential distribution. Green colors indicate suitable areas, and gray colors represent unsuitable ranges on the left; the color gradient indicates variations in habitat suitability on the right (green $=$ highest and pink $=$ lowest); the purple dots show the occurrence points that were used to develop the species distribution model.
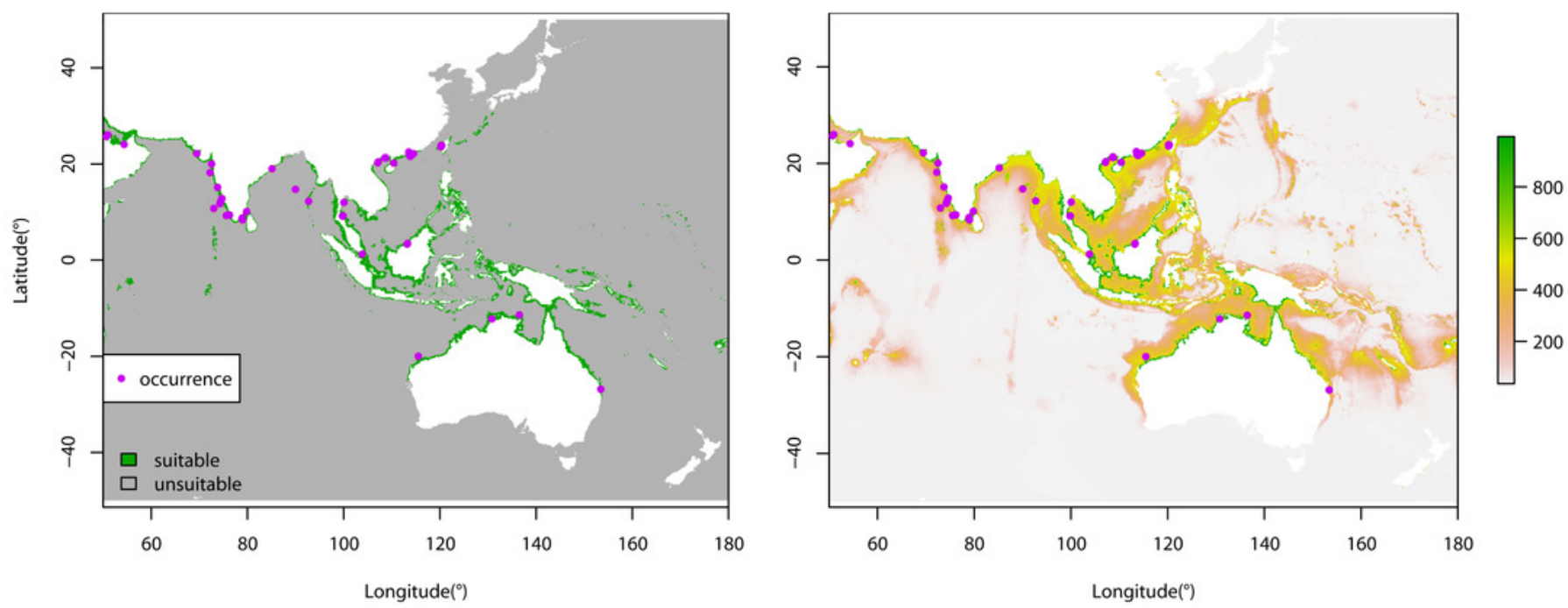


\section{Figure 2}

Range shifts in habitat suitability of Sousa chinensis as projected by the ensemblespecies distribution model between current and future climate conditions.

(A) under the RCP2.6 scenario in the 2050s, (B) under the RCP8.5 scenario in the 2050s, (C) under the RCP2.6 scenario in the 2100s, and (D) under the RCP8.5 scenario in the $2100 \mathrm{~s}$.

Purple indicates areas that will become suitable in the future, dark yellow areas are projected to besuitable under both present-day and future climates, and black represents suitable areas that will become unsuitable in the future. 

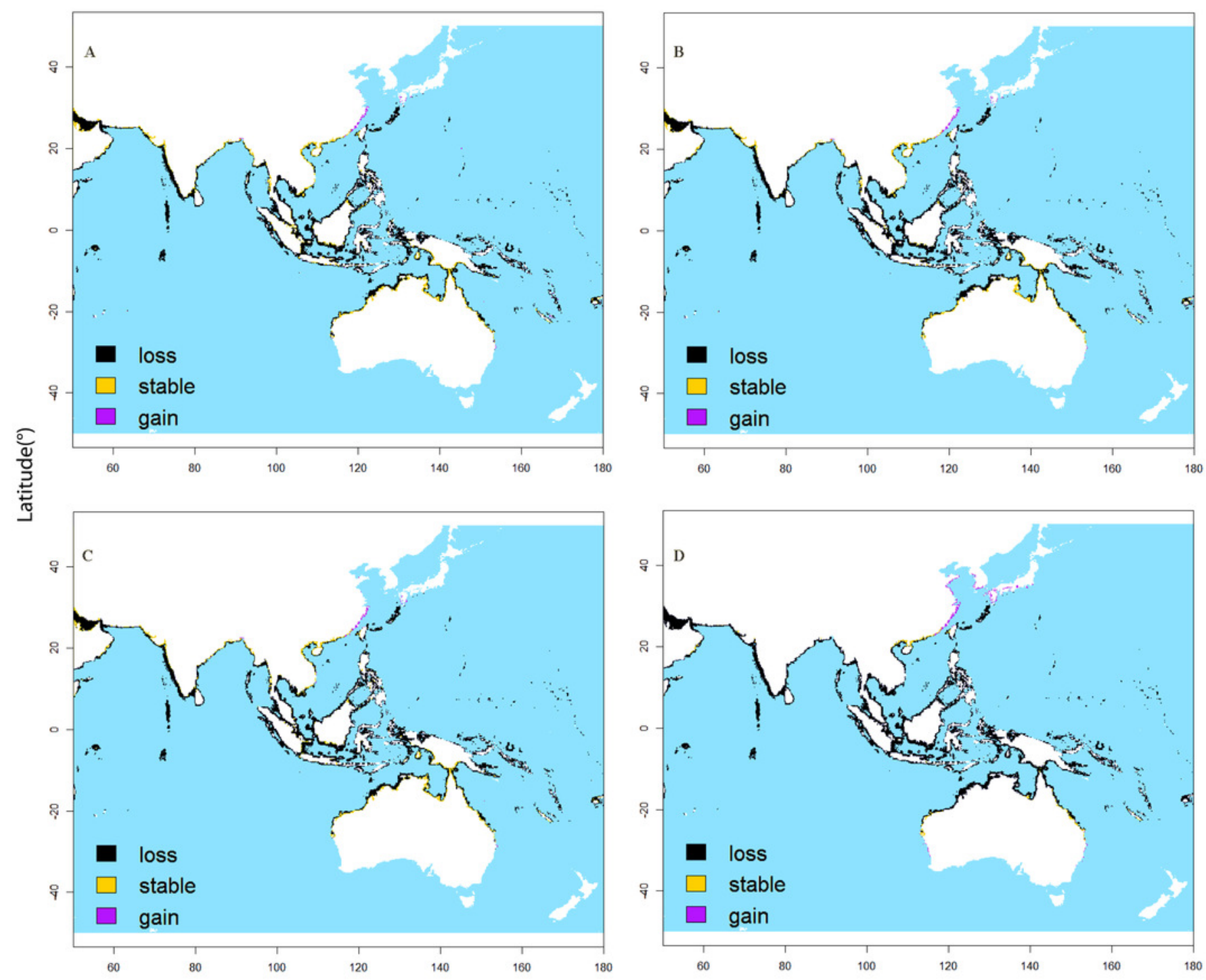

Longitude $\left(^{\circ}\right)$ 


\section{Table $\mathbf{1}$ (on next page)}

Current environmental conditions and the averages and ranges of climatic changes for the future (i.e., the 2050s and 2100s) under different scenarios in the study area.

T: temperature, Sal: salinity, CV: current velocity and Ice: ice thickness. 


\begin{tabular}{|c|c|c|c|c|c|c|c|c|c|}
\hline \multirow{2}{*}{$\begin{array}{l}\text { Environment } \\
\text { Variable }\end{array}$} & \multirow{2}{*}{$\begin{array}{l}\text { Current } \\
\text { value }\end{array}$} & \multicolumn{4}{|c|}{ Changes in $2050 \mathrm{~s}$} & \multicolumn{4}{|c|}{ Changes in $2100 \mathrm{~s}$} \\
\hline & & RCP26 & RCP45 & RCP60 & RCP85 & RCP26 & RCP45 & RCP60 & RCP85 \\
\hline $\mathrm{T}\left({ }^{\circ} \mathrm{C}\right)$ & 22.72 & $\begin{array}{l}0.72 \\
(0.19,1.89)\end{array}$ & $\begin{array}{l}0.96 \\
(0.06,2.35)\end{array}$ & $\begin{array}{l}0.77 \\
(0.81,1.76)\end{array}$ & $\begin{array}{l}1.10 \\
(0.50,2.30)\end{array}$ & $\begin{array}{l}0.63 \\
(0.80,1.87)\end{array}$ & $\begin{array}{l}1.21 \\
(0.24,2.67)\end{array}$ & $\begin{array}{l}1.68 \\
(0.47,3.42)\end{array}$ & $\begin{array}{l}2.87 \\
(1.56,5.53)\end{array}$ \\
\hline Sal(PSS) & 34.51 & $\begin{array}{l}-0.061 \\
(-0.12,0.09)\end{array}$ & $\begin{array}{l}-0.07 \\
(-0.70,0.45)\end{array}$ & $\begin{array}{l}-0.07 \\
(-0.91,0.23)\end{array}$ & $\begin{array}{l}-0.07 \\
(-0.88,0.33)\end{array}$ & $\begin{array}{l}-0.09 \\
(0.88,1.15)\end{array}$ & $\begin{array}{l}-0.13 \\
(-1.03,0.40)\end{array}$ & $\begin{array}{l}-0.16 \\
(-1.64,0.42)\end{array}$ & $\begin{array}{l}-0.26 \\
(-1.97,0.53)\end{array}$ \\
\hline $\mathrm{CV}(\mathrm{m} / \mathrm{s})$ & 0.10 & $\begin{array}{l}0.00 \\
(-0.06,0.09)\end{array}$ & $\begin{array}{l}0.24 \\
(-0.84,1.68)\end{array}$ & $\begin{array}{l}0.25 \\
(-0.84,1.66)\end{array}$ & $\begin{array}{l}0.00 \\
(-0.12,0.09)\end{array}$ & $\begin{array}{l}0.24 \\
(-0.85,1.68)\end{array}$ & $\begin{array}{l}0.13 \\
(-0.84,1.67)\end{array}$ & $\begin{array}{l}0.13 \\
(-0.84,1.67)\end{array}$ & $\begin{array}{l}0.23 \\
(-0.84,1.68)\end{array}$ \\
\hline $\operatorname{Ice}(\mathrm{m})$ & 0.00 & $\begin{array}{l}0.00 \\
(-0.10,0.00)\end{array}$ & $\begin{array}{l}0.00 \\
(-0.12,0.00)\end{array}$ & $\begin{array}{l}0.00 \\
(-0.10,0.00)\end{array}$ & $\begin{array}{l}0.00 \\
(-0.13,0.00)\end{array}$ & $\begin{array}{l}0.00 \\
(-0.12,0.00)\end{array}$ & $\begin{array}{l}0.00 \\
(-0.17,0.00)\end{array}$ & $\begin{array}{l}0.00 \\
(-0.17,0.00)\end{array}$ & $\begin{array}{l}0.00 \\
(-0.17,0.00)\end{array}$ \\
\hline
\end{tabular}




\section{Table 2 (on next page)}

Variation of distribution range (\%) of Sousa chinensis under future climate scenarios.

RCP: representative concentration pathway; PercLoss: percentage of loss; PercGain: percentage of gain; PerStable: percentage of stability. Species range changes were calculated as (suitable range under future climate scenarios - present-day suitable range)/present-day suitable range. 
1

\begin{tabular}{|c|c|c|c|c|c|c|c|c|}
\hline & \multicolumn{4}{|c|}{$2050 \mathrm{~s}$} & \multicolumn{4}{|c|}{$2100 \mathrm{~s}$} \\
\hline & RCP26 & $\mathrm{RCP} 45$ & RCP60 & RCP85 & RCP26 & RCP45 & RCP60 & RCP85 \\
\hline PercLoss & 75.626 & 84.197 & 81.133 & 81.493 & 80.566 & 86.451 & 90.72 & 95.815 \\
\hline PercGain & 3.995 & 3.507 & 3.595 & 3.86 & 3.595 & 3.562 & 3.653 & 5.083 \\
\hline PercStable & 24.374 & 15.803 & 18.867 & 18.507 & 19.434 & 13.549 & 9.28 & 4.185 \\
\hline SpeciesRangeChange & -71.631 & -80.69 & -77.538 & -77.633 & -76.971 & -82.889 & -87.067 & -90.732 \\
\hline
\end{tabular}

2 